\title{
Measuring the Social Return to R\&D
}

\author{
Charles I. Jones \\ Department of Economics \\ Stanford University \\ Stanford, CA 94305 \\ Chad.Jones@Stanford.edu \\ and \\ John C. Williams \\ Board of Governors of the Federal Reserve System \\ Washington, DC 20551 \\ jwilliams@frb.gov
}

February 1997

\begin{abstract}
A large empirical literature reports estimates of the rate of return to $R \& D$ ranging from $30 \%$ to over $100 \%$, supporting the notion that there is too little private investment in research. This conclusion is challenged by the new growth theory. We derive analytically the relationship between the social rate of return to $\mathrm{R} \& \mathrm{D}$ and the coefficient estimates of the empirical literature. We show that these estimates represent a lower bound on the true social rate of return. Using a conservative estimate of the rate of return to $R \& D$ of about $30 \%$, optimal R\&D investment is at least four times larger than actual investment.
\end{abstract}

JEL Classification: O32, O41

Keywords: Social rate of return; research and development; endogenous growth.

Views expressed in this paper are those of the authors and do not necessarily represent those of the Board of Governors of the Federal Reserve System or its staff. 


\section{Introduction}

Do advanced economies engage in too much or too little $\mathrm{R} \& \mathrm{D} ?^{1}$ By how much does private investment in research differ from optimal investment? Given the central role of $R \& D$ as an engine of growth, these questions have spawned a large theoretical and empirical literature. Theory has emphasized the importance of market failures such as imperfect competition and externalities in determining outcomes in the market for new goods and ideas. ${ }^{2}$ However, because there are incentives working to promote both over- and underinvestment in $\mathrm{R} \& \mathrm{D}$, theory alone is unable to provide an unambiguous answer to the sign, much less the magnitude, of the net distortion to R\&D. The empirical literature attempts to resolve this ambiguity by estimating directly the rate of return to $R \& D$ in regressions of productivity growth on R\&D-sales ratios. ${ }^{3}$ The findings of this literature are summarized by Griliches (1992, p. S43):

In spite of [many] difficulties, there has been a significant number of reasonably well done studies all pointing in the same direction: $R \& D$ spillovers are present, their magnitude may be quite large, and social rates of return remain significantly above private rates.

The empirical approach seems to provide a clear answer to the question of whether there is too much or too little private R\&D; it does not, however indicate by how

\footnotetext{
${ }^{0}$ A previous version of this paper was circulated under the title "Too Much of a Good Thing? The Economics of Investment in R\&D.” We would like to thank Roland Benabou, Ken Judd, Michael Horvath, Sam Kortum, Ariel Pakes, Scott Stern, Alwyn Young, and participants of seminars at U.C. Berkeley, Chicago, U.C. Irvine, Michigan, N.Y.U., Penn, U.C.S.D., Stanford, the NBER Summer Institute '95, the NBER Economic Fluctuations meeting, the Conference on Innovation in Strausborg, and the HIID Growth meeting. Financial support from the National Science Foundation (SBR9510916) is gratefully acknowledged.

${ }^{1}$ We should emphasize from the beginning that this paper is not about basic science but rather about applied R\&D undertaken by profit-maximizing firms. Of course, we recognize that the distinction is sometimes difficult to make in practice.

${ }^{2}$ The theoretical literature includes contributions from the IO approach, as reviewed by Tirole (1988), as well as the general equilibrium approach exemplified by Romer (1990), Grossman and Helpman (1991), and Aghion and Howitt (1992).

${ }^{3}$ Recent summaries of this literature include Cohen and Levin (1991), Griliches (1992), and Nadiri (1993).
} 
much R\&D investment needs to be increased.

In fact, theory provides some reason to question the findings of the empirical productivity literature. The results of this literature are nearly all based on a neoclassical theory of growth in which $\mathrm{R} \& \mathrm{D}$ is simply an alternative form of capital investment. This simple capital-based approach ignores many of the distortions associated with research that are formalized by the new growth theory, including monopoly pricing, intertemporal knowledge spillovers, congestion externalities, and creative destruction. Because of these omissions, we may in fact have very little information on the true social rate of return to $R \& D$.

The main contribution of this paper is to link the new growth theory to the empirical results in the productivity literature. We derive analytically the relationship between the social rate of return to $R \& D$ and the coefficient estimates from regressions of total factor productivity growth on $R \& D$ investment. In the process, we provide an intuitive explanation for the various components that make up the social return to $R \& D$. We also derive the relationship between the magnitude of under- or overinvestment in $R \& D$ and the estimated rate of return.

The results are rather surprising. Despite the methodological limitations of the productivity literature-in particular its omission of distortions that might lead to overinvestment-we show that the estimates in this literature represent lower bounds on the social rate of return to $\mathrm{R} \& \mathrm{D}$. Thus, estimates of the rate of return to $R \& D$ from the productivity literature of 30 percent or higher imply that advanced economies like the U.S. substantially underinvest in R\&D. Based on results from the new growth theory, one might be inclined to question the broad conclusions of the productivity literature; in contrast to this intuition, we show that the findings of the productivity literature are extremely robust.

With an estimate of the social return to R\&D in hand, a lower bound on the degree of underinvestment in R\&D can be computed directly. Using a conservative estimate of the social return of $30 \%$ and a private rate of return to capital of $7 \%$, optimal R\&D spending as a share of GDP is more than four times larger than actual spending. 
The methodology developed in this paper allows one to derive these results directly from the production possibilities of the economy - the production function for new ideas and the production function for the consumption/output good. It does not rely on any particular assumptions regarding market structure, the patent system, or distortionary taxes. ${ }^{4}$ More generally, this approach can be applied to a wide variety of models.

The remainder of this paper is organized as follows. We begin in Section 2 with a general derivation of the social rate of return to research. Section 3 reviews the methodology and results of the empirical productivity literature and relates the true social rate of return to $R \& D$ to the estimates in this literature. In section 4 , the magnitude of over- or underinvestment in R\&D is derived and related to the estimated social return, and Section 5 concludes.

\section{The Social Rate of Return to R\&D}

What is the rate of return to society from performing an additional unit of R\&D? To answer this question, we consider the return associated with the following variational argument. Suppose we reallocate one unit of output from consumption to R\&D today, and then consume the proceeds tomorrow. In particular, we reduce $R \& D$ tomorrow to leave the subsequent stock of ideas unchanged. In the market equilibrium, an individual agent is indifferent to this deviation, but in the face of distortions and externalities, society as a whole generally will not be. We define the social rate of return to $R \& D$ to be the gain in consumption associated with this variation. This particular definition turns out to have a number of useful properties that we will now explore.

\footnotetext{
${ }^{4}$ In this sense, it is interesting to compare this approach to Stokey (1995). Stokey, and our own earlier work, address the issue of investment in R\&D by calibrating an R\&D-based growth model. The results in this approach depend critically on how one characterizes the market economy.
} 


\subsection{General Derivation}

We begin with a general derivation of the social rate of return. The first useful result related to our definition is that the social rate of return can be derived solely from the production possibilities of the economy. Typically, only two equations are needed, the production function for ideas and the production function for final output. Let $A$ denote the stock of ideas in the economy. New ideas, the change in $A$, are produced by foregoing consumption of the final output good $Y$, according to some production function $G$ :

$$
A_{t+1}-A_{t}=G\left(R_{t}, A_{t}\right)
$$

where $R$ represents resources devoted to research. We assume that $G$ is increasing in its first argument: more research leads to more ideas. $G$ might be increasing or decreasing in its second argument, depending on the way past ideas affect the current productivity of research. If $\partial G / \partial A>0$, then past inventions raise the productivity of research today, a case that corresponds to "knowledge spillovers" in research. On the other hand, if the best ideas are discovered first, $G$ might be decreasing in $A$.

The consumption/final output good is produced using ideas and a collection of private inputs $X$ according to the production function $F$ :

$$
Y_{t}=F\left(A_{t}, X_{t}\right)
$$

We assume that $F$ is increasing in each of its arguments. Following Romer (1990), one would expect $F$ to exhibit constant returns to $X$ and therefore increasing returns to scale overall.

We will assume the existence of a balanced growth path in which all variables are growing at constant rates over time. This may entail some restrictions on the shapes of $G$ and $F$; we will specialize to the Cobb-Douglas functional forms shortly. Our use of a more general notation is not necessarily intended to suggest generality; rather, it illuminates where each term in the social rate of return comes from. 
The social rate of return to $R \& D$ is computed using the following discrete time variational argument. Suppose we reallocate one unit of output from consumption to $\mathrm{R} \& \mathrm{D}$ at time $t$, and then consume the proceeds in the next period, $t+1$. Moreover, we reduce $\mathrm{R} \& \mathrm{D}$ at time $t+1$ so as to leave the stock of knowledge unchanged from time $t+2$ onward. The total gain in consumption at time $t+1$ associated with this variation is the social rate of return to $R \& D$.

The increase in $A_{t+1}$ associated with a small change in $R_{t}$ is

$$
\nabla A_{t+1}=\left(\frac{\partial G}{\partial R}\right)_{t}
$$

where $\nabla$ is used to denote the change relative to the steady state path. The additional knowledge $\nabla A_{t+1}$ increases output at time $t+1$ by $\left(\frac{\partial Y}{\partial A}\right)_{t+1}$. An additional increase in consumption at time $t+1$ occurs because $R_{t+1}$ can be reduced to leave the path of knowledge unchanged. To determine how much consumption is gained from reducing $\mathrm{R} \& \mathrm{D}$, note that

$$
A_{t+2}=A_{t+1}+G\left(R_{t+1}, A_{t+1}\right) .
$$

Considering the deviation from the balanced growth path,

$$
\nabla A_{t+2}=\nabla A_{t+1}+\left(\frac{\partial G}{\partial R}\right)_{t+1} \nabla R_{t+1}+\left(\frac{\partial G}{\partial A}\right)_{t+1} \nabla A_{t+1} .
$$

The deviation in $\mathrm{R} \& \mathrm{D}, \nabla R_{t+1}$, that will return the stock of knowledge to its original path is found by setting $\nabla A_{t+2}=0$ :

$$
\nabla R_{t+1}=-\frac{(\partial G / \partial R)_{t}}{(\partial G / \partial R)_{t+1}}\left(1+\left(\frac{\partial G}{\partial A}\right)_{t+1}\right) .
$$

The total gain to consumption in period $t+1$ is the sum of the additional output produced and the reduction in $R \& D$ that is made possible. The social rate of return, $\tilde{r}$, is thus given by

$$
1+\tilde{r}=\left(\frac{\partial G}{\partial R}\right)_{t}\left(\frac{\partial Y}{\partial A}\right)_{t+1}+\frac{(\partial G / \partial R)_{t}}{(\partial G / \partial R)_{t+1}}\left(1+\left(\frac{\partial G}{\partial A}\right)_{t+1}\right) .
$$

The intuition behind this equation becomes more transparent if one thinks of knowledge as an asset "purchased" by society, held for a short period of time in 
order to reap a dividend, and then sold. The return can then be thought of as the sum of a dividend and a capital gain (or loss). Let $P_{A, t}$ denote the cost to society of a new idea in units of consumption (the numeraire). Then, because a small change in R\&D leads to $\frac{\partial G}{\partial R}$ new ideas, $P_{A}$ is given by

$$
P_{A, t}=\left(\frac{\partial G}{\partial R}\right)_{t}^{-1}
$$

The rate of change in the cost of producing new ideas, denoted $g_{P_{A}, t}$ equals

$$
g_{P_{A}, t}=\frac{\left(\frac{\partial G}{\partial R}\right)_{t-1}}{\left(\frac{\partial G}{\partial R}\right)_{t}}-1,
$$

which is constant along a balanced growth path.

After rearrangement and substitution, the social rate of return equals

$$
\tilde{r}=\frac{d}{P_{A}}+g_{P_{A}}
$$

where

$$
d=\frac{\partial Y}{\partial A}+\frac{\partial G}{\partial A} P_{A}
$$

In equation (4), $d$ is the "dividend" to society and $g_{P_{A}}$ is the "capital gain." The dividend associated with an additional idea consists of two components. First, the additional knowledge directly raises the productivity of capital and labor in the economy. Second, the additional knowledge changes the productivity of future R\&D investment because of either knowledge spillovers or because subsequent ideas are more difficult to discover. Finally, there is a capital gain or loss associated with any change in the cost of producing new ideas, denoted $g_{P_{A}}$.

\subsection{A Specific Model}

The preceding derivation is purposefully abstract. To make the ideas concrete, we now derive the social rate of return to $R \& D$ using Cobb-Douglas specifications for the final goods and research technologies. For ease of presentation, we switch

\footnotetext{
${ }^{5}$ The second-order cross term $g_{P_{A}} \frac{\partial G}{\partial A}$ has been suppressed.
} 
to continuous time. In this generalized version of Romer's (1990) variety-based endogenous growth model, the final goods technology is given by

$$
Y=A^{\sigma} K^{\alpha} L^{1-\alpha}
$$

where $L$ is labor input, and $K$ is the (aggregated) capital stock. ${ }^{6}$

The production function for new ideas takes the form

$$
(1+\psi) \dot{A}=\tilde{\delta} R=\delta R^{\lambda} A^{\phi} .
$$

Individual researchers take the productivity of research $\tilde{\delta}$ as given. Because they are small relative to the total number of researchers, they view the production of new ideas as taking place with constant returns to research effort $R$. Economywide, however, production of ideas need not be characterized by constant returns. For example, the presence of $0<\lambda \leq 1$ may reflect duplication of effort in the research process: the social marginal product of $R$ may be less than the private marginal product, a classic congestion externality. The parameter $\phi$ measures the net effect of knowledge spillovers and "fishing out" effects in research, both external to atomistic research firms. If the net effect is such that $\phi>0$, we might call this the standing on shoulders effect. The duplication externality associated with $\lambda<1$ might be called the stepping on toes effect.

A third distortion in the research process, highlighted by Grossman and Helpman (1991) and Aghion and Howitt (1992), is associated with creative destruction. That is, new ideas may replace old ideas. Creative destruction can provide an incentive for overinvestment in research in that some innovators earn rents on ideas that are not entirely new. In the market economy, creative destruction affects who gets compensated for which idea, and one has to be careful in describing how this process works. However, in terms of the production possibilities of the model (which are relevant for calculating the social return), introducing creative destruction involves only a minor change. In equation (7), we assume that for every new idea created, $\psi$ "upgrades" are produced that replace existing ideas.

\footnotetext{
${ }^{6}$ We assume that $L$ grows exogenously at rate $n>0$, and capital is accumulated in the standard way, by foregoing consumption.
} 
Figure 1: The Social Return to Research Function

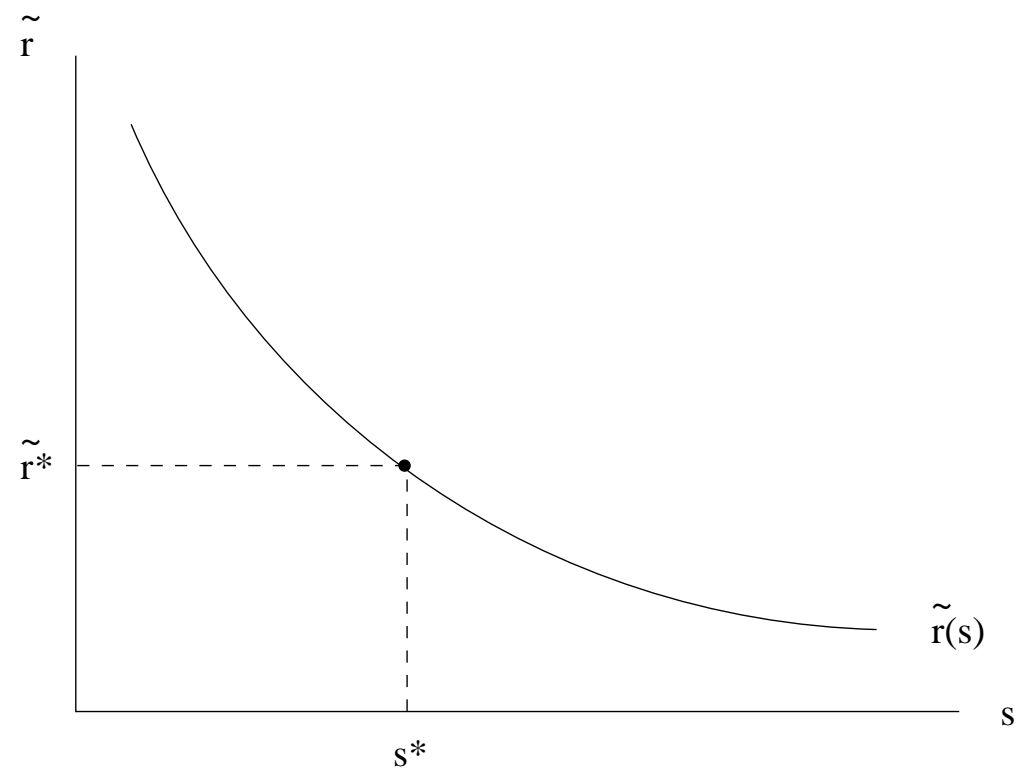

With these functional form assumptions, the social rate of return to R\&D implied by equation (4) is

$$
\tilde{r}(s)=\frac{\lambda \sigma g_{A}}{s}+\phi g_{A}+\left(g_{Y}-g_{A}\right)
$$

where $\tilde{r}(s)$ represents the steady state social rate of return to $\mathrm{R} \& \mathrm{D}$, evaluated at a given steady state R\&D share of total output, $s$. The notation $g_{x}$ is used to indicate the steady state growth rate of the place-holder $x$. The first term on the right-hand side of equation (8) is the dividend associated with extra output, the second term is the dividend associated with knowledge spillovers, and the last term is the capital gain associated with the changing relative value of ideas.

Equation (8) identifies the functional relationship between the social return to research and the share of output invested in research by the economy. This functional relationship is plotted in Figure 1. This figure, together with the analysis in the previous section, motivates our first key result concerning social rates of return: 
The functional relationship between the social rate of return and the share of resources devoted to research depends only on the production possibilities of the economy. Features of the market economy affect the allocation of resources, which determines the point on the social return function.

The attractiveness of this result is that one does not need to make additional assumptions about the nature of the market economy (market structure, patent arrangements, taxes, etc.) to determine the social return to $R \& D$. Provided one can write down an accurate representation of production possibilities, including knowledge of the parameters, one knows the function plotted in Figure 1. Then, one can look at the allocation of resources - the $s$ - actually chosen in the economy and "read off" the social rate of return from the figure.

Why is the functional relationship between the social rate of return and the allocation of resources independent of any market features of the economy? Intuitively, the answer is that no allocative decisions are involved in computing $\tilde{r}$ - we force the economy to do one more unit of $R \& D$ and then calculate the total amount of output than can be consumed with this variation. In this sense, the production possibilities of the model (e.g. the equations describing the social planner's problem) determine the social rate of return function. The market economy and whatever distortions are present determine the allocation of resources - i.e. the point on the social rate of return function. ${ }^{7}$

\footnotetext{
${ }^{7}$ With this in mind, it is interesting to compare our measure of the social rate of return to an alternative calculation, the change in the "value function" of the decentralized economy. This alternative provides the change in welfare associated with additional $R \& D$ taking into account the dynamic response of agents to the variation. However, calculating this alternative requires substantially more structure and effort. First, the value function approach depends critically on the assumptions one makes about market structure and the distortions present in the decentralized economy. As already emphasized, one advantage of our approach is that we do not need this additional structure. Second, analytical solutions are not available with this approach. Finally, in the context of this paper, our calculation is extremely relevant because it is directly related to the estimates in the productivity literature.
} 


\section{Estimating the Social Rate of Return}

Now consider the following question: how can the available data on productivity and $R \& D$ expenditures be used to estimate the social return to $R \& D$ ? One widelyused approach found in the literature is to treat R\&D investment simply as an alternative capital investment in a standard neoclassical model. ${ }^{8}$ The R\&D "stock" is included in the production function, and the partial derivative of output with respect to that stock is treated as the rate of return to R\&D. ${ }^{9}$ The analogy to the marginal product of physical capital is clear. This basic relationship is described by the following two equations:

$$
\begin{aligned}
Y & =e^{\mu t} Z^{\xi} K^{\alpha} L^{1-\alpha}, \\
\dot{Z} & =R,
\end{aligned}
$$

where $Z$ is the measured $R \& D$ stock and we assume no depreciation of the $R \& D$ capital. ${ }^{10}$

In this approach, the marginal product of the $\mathrm{R} \& \mathrm{D}$ stock, $\frac{\partial Y}{\partial Z}$, is interpreted as the rate of return to $\mathrm{R} \& \mathrm{D}$; let's call this marginal product $\tilde{r}^{P L}$. By standard growth accounting logic, estimated TFP growth accounted for by $R \& D$ is then $\tilde{r}^{P L} R / Y$. This motivates the following empirical specification for estimating the rate of return to $R \& D$ :

$$
\Delta \log T F P=\mu+\tilde{r}^{P L} \frac{R}{Y}+\varepsilon .
$$

That is, total factor productivity growth is regressed on the R\&D share of output (and perhaps other control variables as well).

\footnotetext{
${ }^{8}$ A second approach, pursued by Bernstein and Nadiri (1989), is to compute the return to R\&D using estimated cost functions. These two approaches yield similar results as to the return to R\&D.

${ }^{9}$ This basic approach is extended in several directions in the productivity literature. For example, Jaffe (1986) makes progress by incorporating $R \& D$ from other industries into the $R \& D$ stock to estimate the gains from inter-industry spillovers.

${ }^{10}$ This assumption of zero depreciation is somewhat standard in the productivity literature. In general researchers have found that regression estimates are not sensitive to alternative assumptions about the depreciation rate.
} 
The empirical literature distinguishes between the private return and the social return to $\mathrm{R} \& \mathrm{D}$. The former refers to the estimate of $\tilde{r}^{P L}$ using a firm's own $\mathrm{R} \& \mathrm{D}$ share as the explanatory variable. The latter attempts to mitigate measurement problems and to capture interfirm technology spillovers by focusing on the industry level. ${ }^{11}$ Table 1 provides a partial review of estimates of so-defined "social" rates of return from the productivity literature. Estimates of the social return average about 28 percent when only R\&D from one's own industry is included and average nearly 100 percent when the broadest concept of return (the sum of the two columns in the table) is employed. ${ }^{12}$

The framework used in the empirical approach outlined above places two important restrictions on the R\&D stock accumulation process. First, no explicit allowance is made for congestion effects. Second, this approach does not explicitly allow for intertemporal knowledge spillovers or diminishing technological opportunities. Assuming these restrictions on the $R \& D$ technology are violated, the model is misspecified. In this case it is not possible to relate exactly the parameters estimated in the productivity literature to our model parameters. It is possible, however, to obtain a linear approximation to the relationship, accurate in the vicinity of the steady state equilibrium.

Suppose the economy consists of a number of industries, each described by the production possibilities outlined in Section 2. Consider running the (misspecified) regression of the productivity literature in this economy. To determine what this regression will produce, we linearize the production function for ideas given in

\footnotetext{
${ }^{11}$ In regressions with firm-level data, measurement issues are particularly acute. For example, the development of a new high-speed computer may not be reflected in the developing firm's total factor productivity; some of the measured productivity gain may show up downstream. To the extent that product innovations are created and used in the same industry, aggregation to the industry level helps mitigate these problems.

${ }^{12}$ The "used" column reports the additional effect of R\&D conducted in an upstream industry on own productivity. These estimates may be biased downwards due to double counting of R\&D inputs as both R\&D and capital and labor. Schankerman (1981) estimates that adjusting for double-counting raises the estimated rate of return by about 0.1, while Hall and Mairesse (1995) find a bias of only 0.03 to 0.04 .
} 
Table 1: Estimated Rates of Return to R\&D

\begin{tabular}{lccc}
\hline \hline & $(1)$ & $(2)$ & \\
Study & $\tilde{r}$ (own) & $\tilde{r}$ (used) & $(1)+(2)$ \\
\hline & & & \\
Sveikauskas (1981) & $0.17(.06)$ & - & - \\
Hall (1995) & $0.33(.07)$ & - & - \\
Griliches and Lichtenberg (1984b) & $0.34(.04)$ & - & - \\
Terleckyj (1980) & $0.25(.08)$ & $0.82(.21)$ & 1.07 \\
Scherer (1982) & $0.29(.14)$ & $0.74(.39)$ & 1.03 \\
Griliches and Lichtenberg (1984a) & $0.30(.09)$ & $0.41(.20)$ & 0.71 \\
\hline
\end{tabular}

Notes: The left-hand side variable is typically the growth rate of TFP. The righthand side variables include the industry's R\&D intensity (typically R\&D/Sales) and, where indicated, a measure of R\&D intensity of used inputs, along with a constant and other variables. Representative point estimates and associated standard errors of the R\&D intensity coefficients are given in the table.

equation (7) around the balanced growth path. The linear approximation is

$$
\frac{\dot{A}_{t}}{A_{t}} \simeq c+\lambda g_{A} \frac{s_{t}}{\bar{s}}+\lambda g_{A} \ln \left(\frac{Y_{t}}{\bar{Y}_{t}}\right)+(\phi-1) g_{A} \ln \left(\frac{A_{t}}{\bar{A}_{t}}\right),
$$

where $c$ is a constant. Multiplying by $\sigma$,

$$
\frac{d \ln T F P_{t}}{d t} \simeq c+\frac{\lambda g_{T F P}}{\bar{s}} s_{t}+\lambda g_{T F P} \ln \left(\frac{Y_{t}}{\bar{Y}_{t}}\right)+(\phi-1) g_{A} \ln \left(\frac{T F P_{t}}{\overline{T F P_{t}}}\right) .
$$

Regression of the TFP growth rate on the R\&D share of output should yield a coefficient given by

$$
\tilde{r}^{P L}=\frac{\lambda \bar{g}_{T F P}}{\bar{s}} .
$$

There are two potential sources of omitted variable bias, represented by the percent deviations of output and TFP from their respective steady state levels. The sign of the potential bias of not controlling for these terms is ambiguous. In practice, industry and time dummies, capacity utilization rates, and measures of technical 
opportunities are typically included in regressions of this type (see, for example, Clark and Griliches (1984)). This should mitigate the extent to which omitted variable bias enters. In the following, we assume there is no omitted variable bias in estimates of $\tilde{r}^{P L}{ }^{13}$

Now compare the coefficient estimated in the productivity literature with the true social rate of return given by equation (8). The productivity literature captures only the basic output dividend and ignores the dynamic effects associated with the intertemporal knowledge spillover and the capital gain or loss. Mathematically,

$$
\tilde{r}(\bar{s})=\tilde{r}^{P L}+\left(\phi g_{A}+g_{Y}-g_{A}\right) .
$$

As written, it appears that the term determining the difference between the true social return and the estimate from the productivity literature could be either positive or negative. However, this term can be rewritten to reveal that it is always positive, at least in steady state. Along the balanced growth path, $\lambda g_{Y}=(1-$ $\phi) g_{A} \cdot{ }^{14}$ Therefore,

$$
\tilde{r}(\bar{s})=\tilde{r}^{P L}+(1-\lambda) g_{Y}
$$

This equation reveals a rather surprising result:

$\tilde{r}^{P L}$ represents an underestimate of the true social rate of return to $R \& D$ with a maximum downward bias equal to the rate of growth of output.

The general conclusion from this literature that the social rate of return to $R \& D$ is very large evidently survives rigorous analysis in the context of the new growth theory.

How does the productivity literature nearly get the right answer? The explanation involves two different errors that nearly offset. First, the productivity literature focuses on $\frac{\partial Y}{\partial Z}$ as the rate of return to $R \& D$. This focus captures the basic output

\footnotetext{
${ }^{13}$ Monte Carlo simulation evidence based on reasonably sized i.i.d. demand shocks confirms this approximate relationship.

${ }^{14}$ This can be seen by dividing both sides of equation (7) by $A$ and log-differentiating.
} 
effect but ignores two dynamic factors that determine the social rate of return to R\&D in equation (8): intertemporal knowledge spillovers and the "capital gain" (or loss) due to changes in the relative value of knowledge creation over time. The empirical productivity literature implicitly assumes these terms equal zero; in fact both terms may be large in magnitude, but their sum is limited to $(1-\lambda) g_{Y} \cdot{ }^{15}$

The intuition for why the sum of the knowledge spillover and the capital gain terms is bounded is seen by noting that the capital gain reflects the change in the value of ideas. This value equals the cost in terms of consumption goods of producing a new idea, $R / \dot{A}$. From the production function for ideas, one sees that this cost is proportional to $R^{1-\lambda} A^{-\phi}$. The return to society due to the knowledge spillover, $\phi g_{A}$, exactly offsets the capital loss due to the fall in value of ideas as ideas become less costly to generate over time due to the accumulation of knowledge. What remains is the capital gain due to the increase in the value of designs resulting from the growth in $\mathrm{R} \& \mathrm{D}$ and $\lambda<1$, reflected by the term $(1-\lambda) g_{Y}$.

One might expect that the method used in the productivity literature would not correctly incorporate the distortions associated with creative destruction and the monopoly pricing of capital goods. However, the results indicate that these factors enter the rate of return calculation directly through $s$. More generally, distortions associated with the market economy that do not affect the production possibilities of the economy do not affect either the rate of return calculation or the optimal amount of R\&D. Thus, adjustments to estimates of $\tilde{r}^{P L}$ to reflect monopoly pricing, imitation, or creative destruction, as sometimes suggested in the literature, are unnecessary and inappropriate.

\section{The Extent of Underinvestment in R\&D}

One drawback to discussing underinvestment in terms of social rates of return is that the extent of underinvestment is not readily apparent. Fortunately, the analytic

\footnotetext{
${ }^{15}$ We have maintained the assumption that $\lambda \leq 1$, i.e. there are congestion externalities. If instead $\lambda>1$, indicating complementarity between research today apart from knowledge spillovers, then the productivity literature would underestimate the rate of return. Notice, however, that the magnitude of the error is small because of the multiplication by $g_{Y}$.
} 
framework we've used to interpret the estimates from the productivity literature provides this translation. This is apparent from Figure 1: intuitively, in order to find the optimal rate of $R \& D$ investment, all we need to do is invert the social rate of return function.

First, notice that the actual rate of investment in research by the economy, $s^{\text {actual }}$, satisfies the relation

$$
\tilde{r}^{P L}=\frac{\lambda g_{T F P}}{s^{\text {actual }}} .
$$

Second, the optimal amount of research is given by the condition that the social rate of return is equal to the real interest rate, $r .{ }^{16}$ Using this condition and equation (11), the optimal rate of investment in $R \& D$ along a balanced growth path is

$$
s^{\text {optimal }}=\frac{\lambda g_{T F P}}{r-(1-\lambda) g_{Y}} .
$$

Combining this equation with equation (17) gives the ratio of optimal investment to actual investment in research: ${ }^{17}$

$$
\frac{s^{\text {optimal }}}{s^{\text {actual }}}=\frac{\tilde{r}^{P L}}{r-(1-\lambda) g_{Y}} .
$$

With estimates of $\tilde{r}^{P L}$ in mind, we can compute a conservative "lower bound" on this ratio. First, notice that the denominator is no greater than the real rate of return for the economy. Hence, it is no larger than a number like 7 percent, the average real return on the stock market for the last century (Mehra and Prescott, (1985)). Picking a value for $\tilde{r}^{P L}$ of 28 or 30 percent, towards the lower end of the estimates in Table 1, equation (19) implies a conservative estimate of $s^{\text {optimal }} / s^{\text {actual }}$ of about 4 . That is, the optimal share of resources to invest in research is conservatively estimated to be 4 times larger than the actual amount invested by the U.S. economy. The extent of underinvestment is substantial, and could be much larger.

\footnotetext{
${ }^{16}$ This is simply an alternative way to derive the solution to the relevant social planner problem.

${ }^{17}$ Implicit in this derivation is that steady state growth rates are the same in the decentralized (market) and planned economies. This is true because the model considered here is a semi-endogenous growth model like that of Jones (1995). In this model, $g_{A}$ is given by $\lambda n /(1-\phi-\lambda \sigma /(1-\alpha))$. A standard Euler equation for consumption implies that the steady state interest rate is also the same in the two economies.
} 


\section{Conclusion}

Recent endogenous growth models have emphasized the importance of $R \& D$ and the production of knowledge for understanding long run growth. A key issue is whether the economy undertakes too little or too much $\mathrm{R} \& \mathrm{D}$, and by how much. In exploring these questions, we uncover several findings. First, we provide a methodological contribution in showing how to compute social rates of return. For the case of $R \& D$, we establish that the functional relationship between the social rate of return and the share of resources devoted to R\&D depends only on the production possibilities of the economy. Market distortions such as patents, taxes, and monopoly power affect the allocation of resources to $R \& D$, but not the functional relationship itself. Everything we need to know about the market economy is summarized in the observed allocation of resources.

Second, we examine the answer to these questions provided by the empirical productivity literature. A number of studies in that literature purport to find large rates of return to $R \& D$, suggesting substantial underinvestment. We show that these estimates should be interpreted as a lower bound on the true social rate of return, even in light of the distortions to R\&D highlighted by the theoretical literature.

Finally, the approach developed here allows us to go beyond measuring rates of return. Knowledge of the social rate of return function provides a ready mapping between social rates of return and the extent of underinvestment. A conservative estimate indicates that optimal investment in research is more than four times actual investment. 


\section{References}

Aghion, Philippe and Peter Howitt, "A Model of Growth through Creative Destruction," Econometrica, March 1992, 60, 323-351.

Bernstein, Jeffrey I. and M. Ishaq Nadiri, "Research and Development and Intraindustry Spillovers: An Empirical Application of Dynamic Duality," Review of Economic Studies, 1989, 56, 249-269.

Clark, Kim B. and Zvi Griliches, "Productivity Growth and R\&D at the Business Level: Results from the PIMS Data Base," in Zvi Griliches, ed., $R \& D$, Patents and Productivity, Chicago: University of Chicago Press, 1984, pp. 393-416.

Cohen, Wesley M. and Richard C. Levin, "Empirical Studies of Innovation and Market Structure," in Richard Schmalensee and Robert D. Willig, eds., Handbook of Industrial Organization, Elsevier Science Publishers, 1991, chapter 18 .

Griliches, Zvi, "The Search for R\&D Spillovers," Scandinavian Journal of Economics, 1992, 94, 29-47.

and Frank Lichtenberg, "Interindustry Technology Flows and Productivity Growth: A Reexamination, Notes," Review of Economics and Statistics, May 1984, 66 (2), 324-329.

and _ _ "R\&D and Productivity Growth at the Industry Level: Is there Still a Relationship?," in Zvi Griliches, ed., $R \& D$, Patents and Productivity, Chicago: University of Chicago Press, 1984, pp. 465-496.

Grossman, Gene M. and Elhanan Helpman, Innovation and Growth in the Global Economy, Cambridge, MA: MIT Press, 1991.

Hall, Bronwyn H., "The Private and Social Returns to Research and Development: What have we Learned?," June 1995. mimeo. 
and Jacques Mairesse, "Exploring the relationship between R\&D and productivity in French manufacturing firms," Journal of Econometrics, 1995, 65, 263-293.

Jaffe, Adam B., "Technological Opportunity and Spillovers of R\&D: Evidence from Firms' Patents, Profits and Market Value," American Economic Review, December 1986, 76 (5), 984-1001.

Jones, Charles I., "R\&D-Based Models of Economic Growth," Journal of Political Economy, August 1995, 103, 759-784.

Mehra, Rajnish and Edward C. Prescott, "The Equity Premium: A Puzzle," Journal of Monetary Economics, 1985, 15, 145-161.

Nadiri, M. Ishaq, "Innovations and Technological Spillovers," 1993. NBER Working Paper No. 4423.

Romer, Paul M., "Endogenous Technological Change," Journal of Political Economy, October 1990, 98, S71-S102.

Schankerman, Mark, "The effect of double counting and expensing on the measured returns to R\&D," Review of Economics and Statistics, 1981, 63, 454458.

Scherer, Frederic M., "Inter-Industry Technology Flows and Productivity Growth," Review of Economics and Statistics, November 1982, 64 (4), 627634.

Stokey, Nancy L., "R\&D and Economic Growth," Review of Economic Studies, 1995, 62, 469-489.

Sveikauskas, Leo, "Technological Inputs and Multifactor Productivity Growth," Review of Economics and Statistics, May 1981, pp. 275-282.

Terleckyj, Nestor E., "Direct and Indirect Effects of Industrial Research and Development on the Productivity Growth of Industries," in John W. Kendrick 
and Beatrice N. Vaccara, eds., New Developments in Productivity Measurement and Analysis, Chicago: The University of Chicago Press, 1980, chapter 6.

Tirole, Jean, The Theory of Industrial Organization, Cambridge, MA: MIT Press, 1988. 